\title{
Design of a Motorcycle Frame at an Automotive Company in Indonesia
}

\author{
Djoko Setyanto $^{1 *}$, Arka Dwinanda Soewono ${ }^{2}$, Andi Wibowo ${ }^{3}$ and Rugerri Toni Liong ${ }^{4}$ \\ ${ }^{1}$ Associate Professor, Department of Mechanical Engineering, Atma Jaya Catholic University of Indonesia, Indonesia. \\ ${ }^{2}$ Assistant Professor, Department of Mechanical Engineering, Atma Jaya Catholic University of Indonesia, Indonesia. \\ ${ }^{3}$ Senior Manager Technical Administrative Department, PQE Division, PT Astra Honda Motor, Indonesia.
}

${ }^{4}$ Associate Professor, Department of Institute of Engineering Mechanics, Karlsruhe Institute of Technology, Germany.

\begin{abstract}
Experimental tests used in the automotive industry in Indonesia to evaluate the effectiveness of a new motorcycle frame design are costly and time-consuming. A valid FiniteElement (FE) model can be employed to replace the experimental testing. This paper describes how to create a FE model of a new design of a motorcycle frame at an automotive company in Indonesia. The first step is to develop a 3D solid model of the frame by using Catia V5R25 software. Based on this model, the actual frame prototype was built from STAM 390 pipe material and welded together by DR4000 welding robot using MIG welding process. The next step is to revise the 3D solid model based on the geometries of the actual prototype obtained from the 3D Scan GOM Atos Triple Scan II. In addition, the 3D model of the frame is assumed to have bead welding on all welded joints. Meshing of the FE model is generated using Sim-Designer 2017 software. Finite element analysis (FEA) is done using Nastran 2014 SOL 103 in order to obtain the dynamic characteristic of the FE model. To validate the FE model, the experimental modal analysis (EMA) of the actual frame prototype is performed. The frame prototype is hanged under free-free condition on a fixed jig and subjected to the impact hammer test. Frequency response function (FRF) was then obtained from the ratio of a response and a force that is acquisition in a dynamic signal analyser. The eigenvalue from the EMA is used to validate the eigenvalue of the FEA. The frame model is then subjected to corresponding constraints to simulate the actual driving condition of the motorcycle. The frequency response from the simulation shows that the dominant response occurs at the first natural frequency of $3 \mathrm{~Hz}$. Safety analysis of the frame structure can be carried out based on these resonance conditions. The proposed method provides a useful tool for the analysis and design of a new motorcycle framework.
\end{abstract}

Keywords: Finite element, modal analysis, eigenvalue, motorcycle frame

\section{INTRODUCTION}

The development of new products in the motorcycle industry must respond quickly to market demand [1]. Frame is one of the most important components of a motorcycle and hence, new motorcycle models always require new frames. The process of designing a new motorcycle frame begins with making a 3D technical drawing. Based on the 3D technical drawing, the actual frame prototype is then realized and tested using the designed forces or loads for analysing the frame strength. The previous 3D model was then updated based on the feedback from those test results. After that, the improved prototype is made and the cycle continues until the final prototype is considered to meet safety standards. This iterative process not only requires a long time but also significant cost [2].

This problem can be reduced by using a virtual model as an alternative to the iterative process on the prototype updating and testing [3]. Rashid et al [4] successfully employed virtual method based on Computer-Aided Design (CAD) and Computer-Aided Engineering (CAE) model generated by CATIA V5R18 software to design a superbike paddock stand which was subsequently verified by experimental testing. Experimental results are also used to verify motorcycle frame models as performed by Cali and Oliveri [5] and Doria and Taraborrelli [6]. Correspondingly, Katdare and Shilwant [7] have used CATIA V5 to optimize the design and reduce the weight of a vehicle chassis frame. Optimization of frame modeling to get weight reduction with sufficient stiffness from the frame are also done by Scappaticci et al [8], Bala Manikandan et al [9] and Li and Feng [10]. The all studies demonstrated that the use of the software shorten the time in the product development process.

The commonly used virtual method in automotive industry is based on a Finite Element (FE) model. In the previous study by Jelani et al [11], a valid FE model of a motorcycle chassis was successfully generated using CAD software. They suggested that the three sensitive parameters for updating FE model are Young's Modulus, Density, and Poisson's ratio; while also recommended that the FE model should be equipped with a welding model. Similar attempt was made by 
Covill et al [12] to generate FE model using beam elements to represent a standard road bicycle frame. Both studies highlight the usefulness of FE model in designing vehicle frame, as well as the fact that the FE model must be valid to illustrate the similarity of the model with the actual condition of the prototype testing. The validity of the FE model can be ensured by comparing its dynamic parameters to the actual prototype parameters, with the most commonly used parameter is eigenvalue or natural frequencies [13].

In addition, a FE model combined with Modal Analysis has often been used for stress analysis. Mohankumar et al [14] employed this method to identify critical stress areas of a scooter frame model made using ANSYS software. The modal analysis was also successfully used by Hatifi et al [15] and Bucchi and Ceru [16] to validate FE model of joining two plates by MIG welding and frame and the tires behaviour. Likewise, Abdullah et al [17] performed a model updating of a go-kart chassis structure in order to reduce the percentage of error between the experimental modal analysis and finite element analysis. Optimization of the selected parameter was able to revise the modal data of the FE model and increase its accurateness. The valid FE model can replace the iteration process of making a new prototype and it tests in order to eliminate time-consuming, cumbersome, and error-prone tasks. These studies can be used as a reference for designing a new frame of motorcycle. This paper describes how to create a valid FE model of a new design of a motorcycle frame by an automotive company in Indonesia.

\section{METHOD AND EXPERIMENTAL PROCEDURE}

The procedure for creating a FE model of a new motorcycle frame which can be analysed through the experimental vibration (experimental modal analysis) method is depicted in Figure 1. The commercial software, Computer-Aided Design (CAD) is employed to generate the technical drawing and the FE model of the motorcycle frame. With the aim of producing an accurate representation, the geometry of the FE model is then evaluated based on the real prototype.

A 3D Scan GOM Atos Triple Scan II is used to scan and measure the geometries of the actual frame prototype as shown in Figure 2. These data are then used to improve the $\mathrm{CAD}$ model of the motorcycle frame.

In order to validate the FE model, the experimental modal analysis is conducted. The procedure of the experimental vibration is illustrated in Figure 3. In the experiment, the frame prototype is hung freely using rubber ropes on a rigid jig and excited by an impact hammer. This excitation method is chosen because the size of the frame prototype is relatively small [18]. The excitation force applied to the prototype will provide sufficient responses that can be detected by the accelerometer installed at another point on the frame.

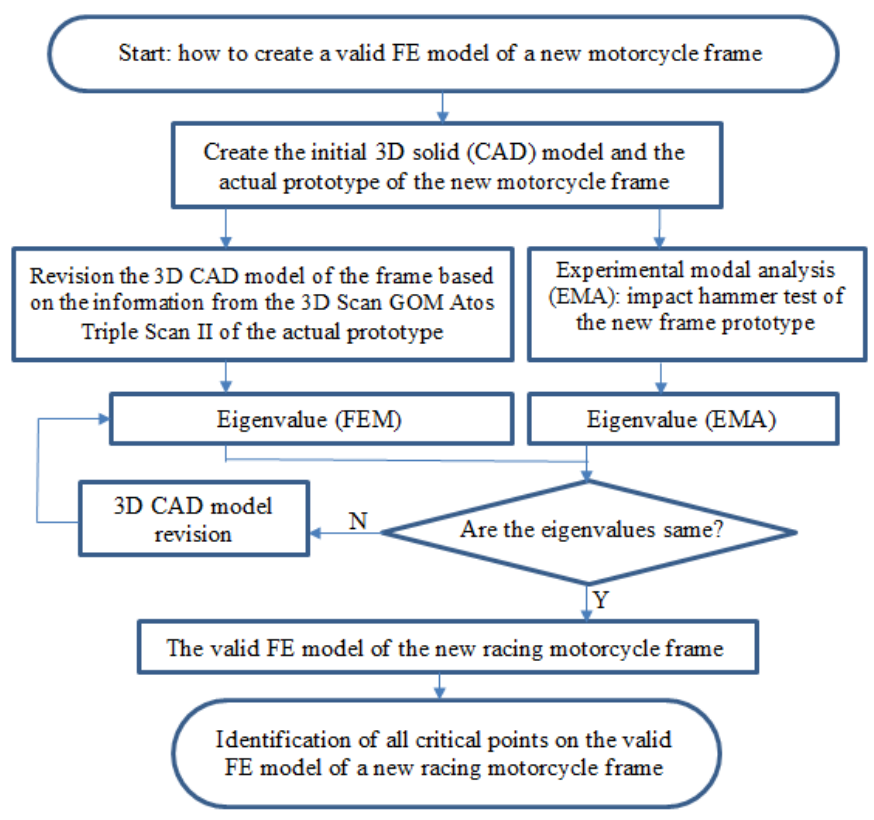

Fig. 1. Method for creating a valid FE model of a new motorcycle frame
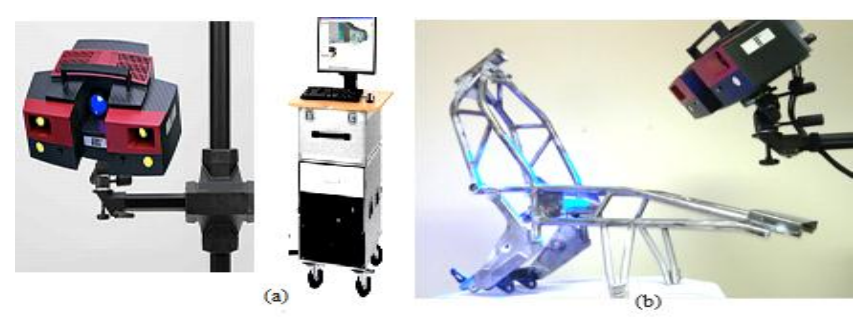

Fig. 2. (a) 3D Scan GOM Atos Triple Scan II; (b) Scanning of the prototype
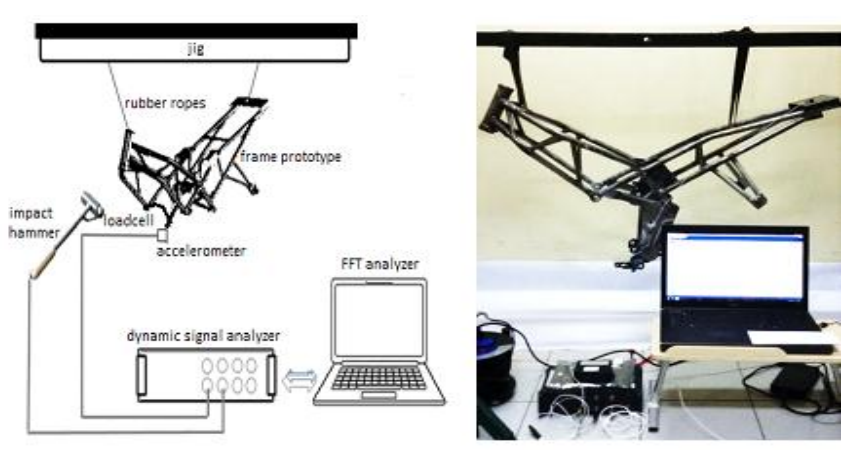

Fig. 3. The experimental procedure of modal analysis

The data obtained from the experimental vibration test is the frequency response function (FRF). If the measurement of vibration response uses an accelerometer, the FRF obtained is in the form of inertance or receptance. Modal analysis is then used to determine the natural frequency (eigenvalue), damping factor, and vibration mode shape (eigenvector) of the 
structure $[19,20]$. In this study, the parameter used to validate the FE model is eigenvalue.

\section{FE MODEL OF A NEW MOTORCYCLE FRAME}

The initial 3D model of a new motorcycle frame done on Catia V5R25 software is shown in Figure 4. This model is used as the basis for the actual prototype that will be subjected to the vibration analysis.

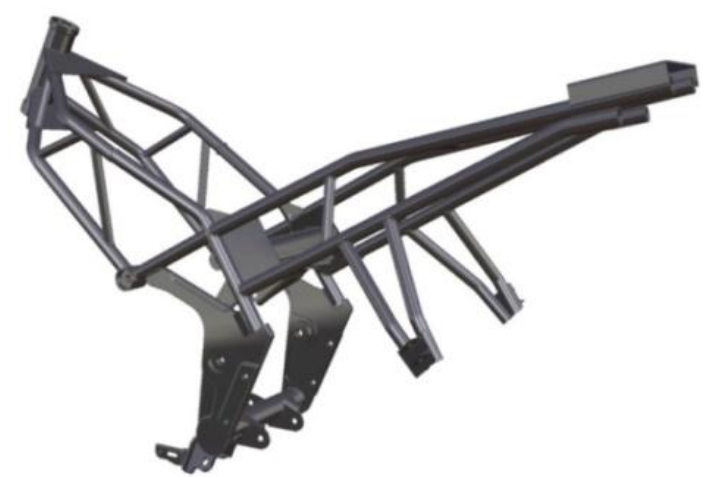

Fig. 4. The initial 3D solid model of a new motorcycle frame

The next step is to manufacture the actual frame prototype. It is made based on the technical drawing of the initial 3D model above. The $3 \mathrm{D}$ model is than plotted into a $2 \mathrm{D}$ drawing. It used for the MIG welding process by the DR4000 welding robot. The chosen material for the actual frame prototype is STAM 390 consisting of 2-mm diameter pipes with 1.6-mm thickness. In addition, the frame is also reinforced with smaller pipes (16-mm in diameter and 1-mm wall thickness), as well as cross plates (2-mm thickness). The welding robot, the welding process and actual prototype of the new motorcycle are depicted in Figure 5.

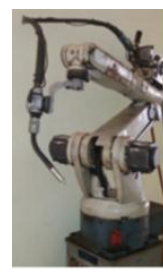

(a)

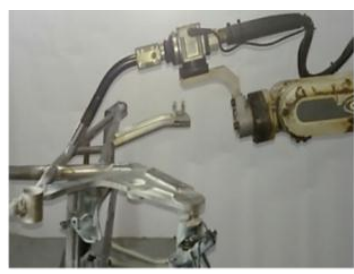

(b)

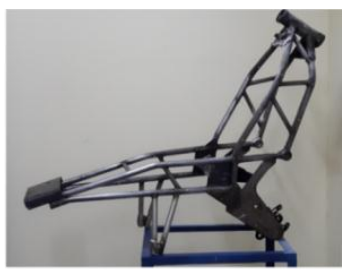

(c)
Fig. 5. (a) DR4000 welding robot; (b) Welding process; (c) Actual prototype

Due to deform after welding process of the prototype, there are deviations between the dimensions of the actual prototype and the initial 3D model of the motorcycle frame. The deviations range from $0.2-\mathrm{mm}$ to $14.8-\mathrm{mm}$. A revised CAD model that matches the actual dimension of the prototype is created based on the information provided by scanning the prototype using 3D Scan GOM Atos Triple Scan II. The dimension of the 3D model is adjusted by best fit method. Bead welds are added to all connections of the corrected model so that they are similar to the actual condition of the prototype [11]. The dimensions between the revised model and the actual prototype are relatively the same. The deviations of dimension that occur are relatively small, maximum only $0.6-\mathrm{mm}$ at the main section of the frame body. The revised 3D solid model and deviations of the model with respect to the actual prototype are described in Figure 6.

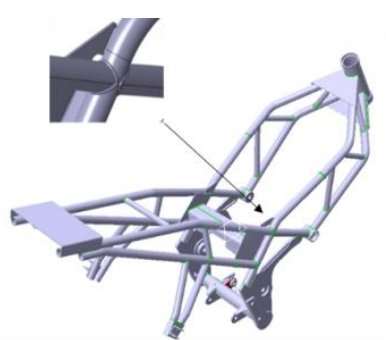

(a)

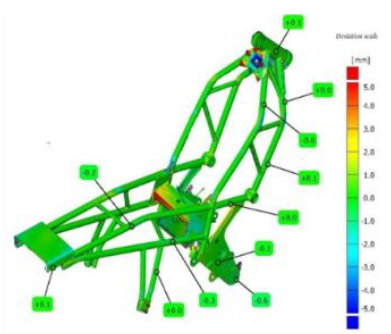

(b)
Fig. 6. (a) The revised 3D model of the frame; (b) Deviations between the revised 3D solid model and the actual prototype

The meshes for the FE analysis of the revised 3D solid model vibration are generated using SimDesigner V2017 software. The chosen mesh type is tetrahedral 10 with meshing sizes of $20,15,10,7$, and 4 [21]. The resulted numbers of nodes and elements (meshes) are summarized in Table 1. Smaller the mesh size (i.e., more nodes) will produce more accurate result at the expense of longer computer processing time.

Table 1. Type of meshing

\begin{tabular}{|c|c|c|c|c|c|}
\hline \multirow{2}{*}{ Number of } & \multicolumn{5}{|c|}{ Meshing size } \\
\cline { 2 - 6 } & $\mathrm{m} 20$ & $\mathrm{~m} 15$ & $\mathrm{~m} 10$ & $\mathrm{~m} 7$ & $\mathrm{~m} 4$ \\
\hline Nodes & 82,935 & 98,968 & 163,606 & 284,600 & 807,018 \\
\hline Elements & 41,844 & 49,753 & 82,206 & 143,616 & 418,896 \\
\hline
\end{tabular}

The solid mesh of the revised frame model is drawn in Figure 7.

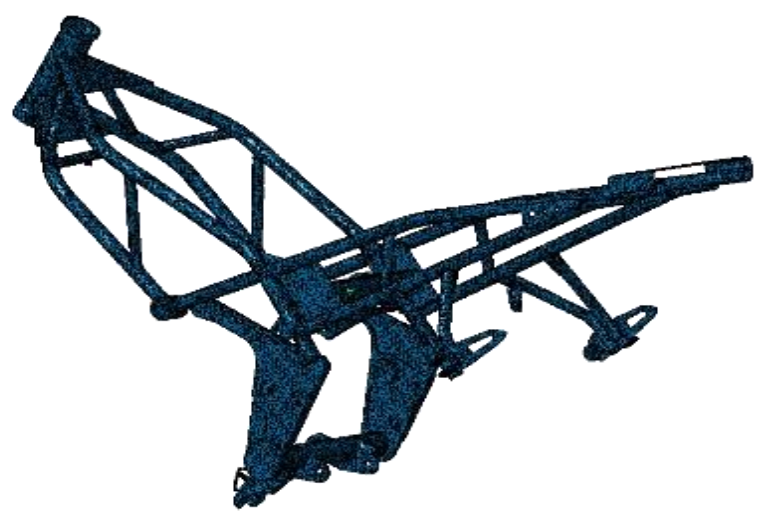

Fig. 7. Solid mesh of the revised frame model 
Dynamic simulations of the FE model by using MSC Nastran 2014 SOL 103 produced eigenvalue as listed in Table 3.

Table 3. Eigenvalue of FE model of the revised frame model for different mesh sizes

\begin{tabular}{|c|c|c|c|c|c|}
\hline \multirow{2}{*}{ Mode } & \multicolumn{5}{|c|}{ Eigenvalue (Natural Frequencies) } \\
\cline { 2 - 6 } & $\mathrm{m} 20(\mathrm{~Hz})$ & $\mathrm{m} 15(\mathrm{~Hz})$ & $\mathrm{m} 10(\mathrm{~Hz})$ & $\mathrm{m} 7(\mathrm{~Hz})$ & $\mathrm{m} 4(\mathrm{~Hz})$ \\
\hline $1^{\text {st }} \operatorname{mode}\left(\mathrm{f}_{\mathrm{n} 1}\right)$ & 81.119 & 90.847 & 82.112 & 81.290 & 79.038 \\
\hline $2^{\text {nd }} \operatorname{mode}\left(\mathrm{f}_{\mathrm{n} 2}\right)$ & 95.560 & 93.827 & 98.219 & 97.094 & 92.876 \\
\hline $3^{\text {rd }} \operatorname{mode}\left(\mathrm{f}_{\mathrm{n} 3}\right)$ & 107.510 & 101.170 & 109.110 & 107.750 & 104.320 \\
\hline $4^{\text {rd }} \operatorname{mode}\left(\mathrm{f}_{\mathrm{n} 4}\right)$ & 115.350 & 114.670 & 113.640 & 111.850 & 109.530 \\
\hline $5^{\text {rd }} \operatorname{mode}\left(\mathrm{f}_{\mathrm{n} 5}\right)$ & 141.130 & 132.340 & 139.000 & 135.120 & 130.620 \\
\hline $6^{\text {rd }} \operatorname{mode}\left(\mathrm{f}_{\mathrm{n} 6}\right)$ & 148.810 & 138.420 & 141.090 & 137.120 & 133.110 \\
\hline $7^{\text {rd }} \operatorname{mode}\left(\mathrm{f}_{\mathrm{n} 7}\right)$ & 154.810 & 155.570 & 152.320 & 148.920 & 144.580 \\
\hline $8^{\text {rd }} \operatorname{mode}\left(\mathrm{f}_{\mathrm{n} 8}\right)$ & 194.740 & 190.870 & 192.160 & 188.480 & 183.660 \\
\hline $9^{\text {rd }} \operatorname{mode}\left(\mathrm{f}_{\mathrm{n} 9}\right)$ & 208.370 & 206.220 & 198.400 & 193.500 & 187.630 \\
\hline
\end{tabular}

\section{MODAL ANALYSIS AND VALIDATION OF FE MODEL}

The impact force from the hammer to the frame prototype as well as frequency response function (inertances in the $\mathrm{x}$-axis, $\mathrm{y}$-axis, and z-axis) are shown in Figure 8. Horizontal axis shows time or frequency while vertical axis represents force or ratio of acceleration and force. Inertance generated in the $\mathrm{x}$ axis indicate five natural frequencies, the $3^{\text {rd }}, 4^{\text {th }}, 5^{\text {th }}, 6^{\text {th }}$, and $9^{\text {th }}$. Meanwhile inertance in the y-direction indicate 6 natural frequencies with two of them, the $1^{\text {st }}$ and $8^{\text {th }}$ being two additional frequencies that are not visible in the $\mathrm{x}$-axis direction. The inertance in z-direction displayed 9 natural frequencies with the $2^{\text {nd }}$ and $7^{\text {th }}$ being two frequencies that are not visible in the $\mathrm{x}$-axis and $\mathrm{y}$-axis directions.
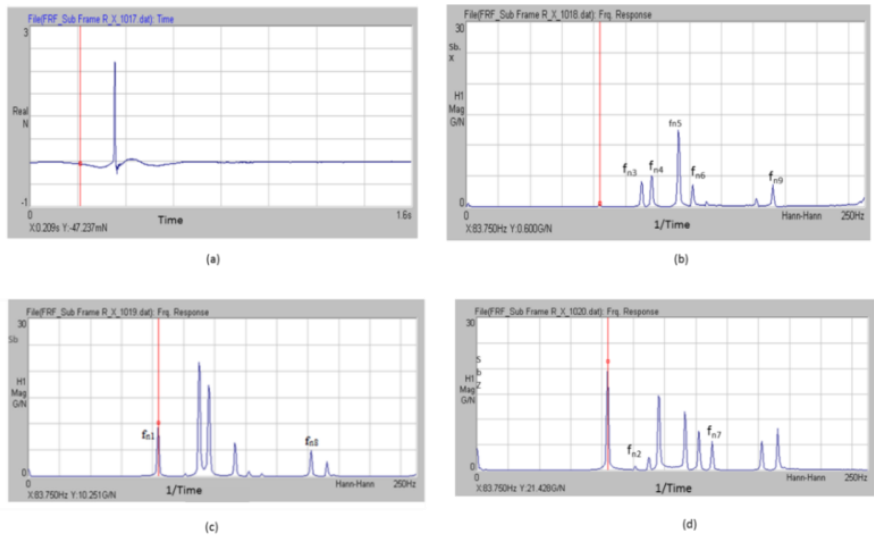

Fig. 8. (a) Impact hammer force; (b) Inertance in the $x$-axis; (c) Inertance in the $y$-axis; (d) Inertance in the $\mathrm{z}$-axis

Eigenvalue from the frequency response functions data are summarized in Table 4. Those eigenvalue is used as a reference to validate the eigenvalue result from the FE model.

The validation of the FE model to the prototype was done by comparing the two eigenvalues. The reference for comparison is the experimental results or experimental modal analysis. If the difference (error) is below 10\%, then the FE model is considered valid enough [15-17]. Table 5 lists the comparison of eigenvalues between the FEM (m20, m15, m10, m7, m4) and the results from the EMA. It can be seen that the errors are below $10 \%$ for all meshing types $(\mathrm{m} 20, \mathrm{~m} 15, \mathrm{~m} 10, \mathrm{~m} 7$, and $\mathrm{m} 4$ ) so that the FE model is considered valid. As expected, relatively smaller errors are found for meshing $\mathrm{m} 10$, $\mathrm{m} 7$ and $\mathrm{m} 4$ compare to $\mathrm{m} 20$ and $\mathrm{m} 15$. Thus, smaller meshing sizes (i.e. $\mathrm{m} 10, \mathrm{~m} 7$, or $\mathrm{m} 4$ ) will be employed to get the critical location of the FE model being simulated against the loads. Meshing size $\mathrm{m} 7$ is the preferred meshing for further analysis to determine the critical locations on the frame because the average of the errors is the smallest.

Table 4. Eigenvalue from the experimental modal analysis (EMA) of the frame prototype

\begin{tabular}{|c|c|}
\hline Mode & Eigenvalue (Natural Frequencies) \\
\hline $1^{\text {st }}$ mode $\left(f_{n 1}\right)$ & $83.75 \mathrm{~Hz}$ \\
\hline $2^{\text {nd }}$ mode $\left(f_{n n}\right)$ & $101.88 \mathrm{~Hz}$ \\
\hline $3^{\text {rd }}$ mode $\left(f_{n 3}\right)$ & $110.63 \mathrm{~Hz}$ \\
\hline $4^{\text {rd }}$ mode $\left(f_{n 4}\right)$ & $116.25 \mathrm{~Hz}$ \\
\hline $5^{\text {rd }}$ mode $\left(f_{n 5}\right)$ & $113.125 \mathrm{~Hz}$ \\
\hline $6^{\text {rd }} \operatorname{mode}\left(f_{n 6}\right)$ & $141.875 \mathrm{~Hz}$ \\
\hline $7^{\text {rd }}$ mode $\left(f_{n 7}\right)$ & $150.625 \mathrm{~Hz}$ \\
\hline $8^{\text {rd }} \operatorname{mode}\left(f_{n 8}\right)$ & $182.5 \mathrm{~Hz}$ \\
\hline $9^{\text {rd }} \operatorname{mode}\left(f_{n 9}\right)$ & $192.5 \mathrm{~Hz}$ \\
\hline
\end{tabular}

Table 5. The comparison of eigenvalues between model simulations and experiment

\begin{tabular}{|c|c|c|c|c|c|}
\hline \multirow[t]{3}{*}{ Mode } & \multicolumn{5}{|c|}{ Eigenvalues (Natural Frequencies) } \\
\hline & \multirow{2}{*}{$\begin{array}{c}\text { EMA } \\
(\mathrm{Hz})\end{array}$} & \multicolumn{4}{|c|}{$\mathrm{m} 20$} \\
\hline & & \multicolumn{2}{|c|}{ FEM (Hz) } & \multicolumn{2}{|c|}{ Error $(\%)$} \\
\hline $1^{\text {st }}$ & 83.75 & \multicolumn{2}{|c|}{81.12} & \multicolumn{2}{|c|}{3.141} \\
\hline $2^{\text {nd }}$ & 101.88 & \multicolumn{2}{|c|}{95.56} & \multicolumn{2}{|c|}{6.199} \\
\hline $3^{\text {rd }}$ & 110.63 & \multicolumn{2}{|c|}{107.51} & \multicolumn{2}{|c|}{2.816} \\
\hline $4^{\text {rd }}$ & 116.25 & \multicolumn{2}{|c|}{115.35} & \multicolumn{2}{|c|}{0.774} \\
\hline $5^{\text {rd }}$ & 113.16 & \multicolumn{2}{|c|}{141.13} & \multicolumn{2}{|c|}{6.013} \\
\hline $6^{\text {rd }}$ & 141.88 & \multicolumn{2}{|c|}{148.81} & \multicolumn{2}{|c|}{4.888} \\
\hline $7^{\text {rd }}$ & 150.63 & \multicolumn{2}{|c|}{154.81} & \multicolumn{2}{|c|}{2.778} \\
\hline $8^{\text {rad }}$ & 182.50 & \multicolumn{2}{|c|}{194.74} & \multicolumn{2}{|c|}{7.443} \\
\hline grad & 192.50 & \multicolumn{2}{|c|}{208.37} & \multicolumn{2}{|c|}{8.244} \\
\hline \multirow[t]{3}{*}{ Mode } & \multicolumn{5}{|c|}{ Eigenvalues (Natural Frequencies) } \\
\hline & \multirow{2}{*}{$\begin{array}{c}\text { EMA } \\
(\mathrm{Hz})\end{array}$} & \multicolumn{2}{|c|}{$\mathrm{m} 15$} & & \\
\hline & & $\mathrm{FEM}(\mathrm{Hz})$ & Error $(\%)$ & FEM $(\mathrm{Hz})$ & Error $(\%)$ \\
\hline $1^{\text {st }}$ & 83.75 & 90.85 & 8.474 & 82.11 & 1.956 \\
\hline $2^{\text {nd }}$ & 101.88 & 93.83 & 7.900 & 98.21 & 3.589 \\
\hline $3^{\text {rd }}$ & 110.63 & 101.17 & 8.547 & 109.11 & 1.369 \\
\hline $4^{\text {rad }}$ & 116.25 & 114.67 & 1.359 & 113.64 & 2.245 \\
\hline $5^{\text {rd }}$ & 113.16 & 132.34 & 0.590 & 139.00 & 4.413 \\
\hline $6^{\text {rd }}$ & 141.88 & 138.42 & 2.435 & 141.09 & 0.553 \\
\hline $7^{\text {rd }}$ & 150.63 & 155.57 & 3.283 & 152.32 & 1.125 \\
\hline $8^{\text {rd }}$ & 182.50 & 190.87 & 5.308 & 192.16 & 6.019 \\
\hline grd $^{\text {rad }}$ & 192.50 & 206.22 & 7.127 & 198.40 & 3.065 \\
\hline Mode & & Eigenva & (Natural F & quencies) & \\
\hline & EMA & & & & \\
\hline & $(\mathrm{Hz})$ & FEM (Hz) & Error (\%) & FEM $(\mathrm{Hz})$ & Error $(\%)$ \\
\hline $1^{\text {st }}$ & 83.75 & 81.29 & 2.937 & 79.04 & 5.626 \\
\hline $2^{\text {nd }}$ & 101.88 & 97.09 & 4.693 & 92.88 & 8.833 \\
\hline $3^{\text {rd }}$ & 110.63 & 107.75 & 2.599 & 104.32 & 5.699 \\
\hline $4^{\text {rd }}$ & 116.25 & 111.85 & 3.785 & 109.53 & 5.781 \\
\hline $5^{\text {rd }}$ & 113.16 & 135.12 & 1.499 & 130.62 & 1.882 \\
\hline $6^{\text {nd }}$ & 141.88 & 137.12 & 3.352 & 133.11 & 6.178 \\
\hline $7^{\text {rd }}$ & 150.63 & 148.92 & 1.132 & 144.58 & 4.013 \\
\hline $8^{\text {rad }}$ & 182.50 & 188.48 & 3.989 & 183.66 & 1.330 \\
\hline grd & 192.50 & 193.50 & 0.519 & 187.63 & 2.530 \\
\hline
\end{tabular}




\section{FE MODEL OF THE REAL FRAME}

The valid frame model is then equipped with constraints that describe the conditions of the real frame as a motorcycle. The constraint given is to illustrate the frame of a motorcycle in a unity with the engine, steering and suspension system. Front and rear suspension systems are modelled as 1D spring elements. To connect the pivot centre of frame body and centre of load was used 1D beam rigid element. The engine load of $27 \mathrm{~kg}$ and $75 \mathrm{~kg}$ of person loads are considered as loads received by the frame FE model. The spring and damping coefficients for the front and rear suspension are taken respectively $9.42 \mathrm{~N} / \mathrm{mm}$ and $0.05 \mathrm{Ns} / \mathrm{mm}$ for the front suspension and $88.1 \mathrm{~N} / \mathrm{mm}$ and $4.1 \mathrm{Ns} / \mathrm{mm}$ for the rear suspension [22]. The FE model to illustrate the real frame is shown in Figure 9. The natural frequencies of the frame in the resonant frequency range of the highway $1-100 \mathrm{~Hz}$ [23] as a result of MSC Nastran 2014 SOL 103 occur at $3 \mathrm{~Hz}, 55.3 \mathrm{~Hz}$ and $91.4 \mathrm{~Hz}$.

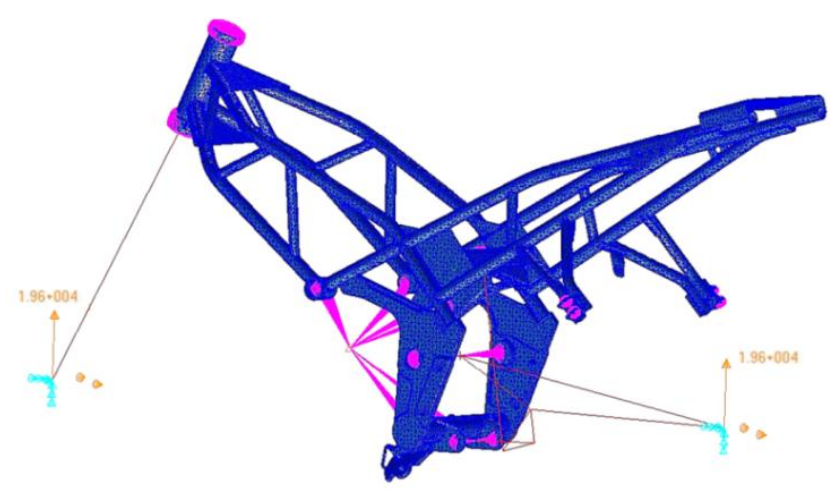

Fig. 9. FE model of the real frame

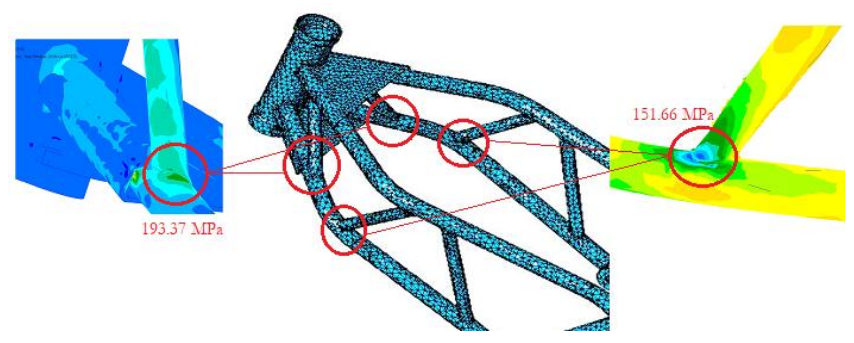

Fig. 10. Critical areas and von Mises stress

The frequency response analysis of the frame was performed using MSC Nastran 2014 SOL111. The frequencies of 1-100 $\mathrm{Hz}$ are given with $2 \mathrm{G}$ acceleration load at the two positions centre of the front and rear axles in the $\mathrm{Z}$ direction. The measurement point is taken at two positions to determine the response when the load is applied. The first measurement is on the steering system and the second on the rear crossbar. The frequency response results show that the dominant response occurs at the first natural frequency of $3 \mathrm{~Hz}$. The first mode at $3 \mathrm{~Hz}$ and the critical areas are depicted in Figure 10. The maximum principle stresses are $193.37 \mathrm{MPa}$ and 151.66 MPa as shown in Figure 10. These stresses are smaller than $235 \mathrm{MPa}$, the yield stress of STAM 390, so it is concluded that the frame structure is safe.

\section{CONCLUSIONS}

This paper describes how to develop the FE model of a new frame of a motorcycle at the automotive industry in Indonesia. The FE model is validated through a comparison of eigenvalues generated from experimental modal analysis. The valid FE model is then given constraints and loads that describe a single unit as a motorcycle. Those valid FE model then be evaluated for safety and durability through simulated loading on the FE model. Corrective actions on the structural FE model can then be quickly carried out to fulfill the design requirements. The valid $\mathrm{FE}$ model can replace the iteration process of making a new prototype and it tests in order to eliminate time-consuming, cumbersome, and error-prone tasks.

Based on the experimental and simulation study presented, the following conclusions can be drawn:

1) A valid finite element model of a motorcycle frame is successfully created by using Catia V5R25. The model is built using a tetrahedral mesh of size $\mathrm{m} 7$, containing 143,616 meshes with a number of nodal of 284,600 . Furthermore, it is validated based on the eigenvalue of the experimental modal analysis (EMA) from the actual prototype.

2) The frequency response show that the dominant response occurs at the first natural frequency of $3 \mathrm{~Hz}$. There are four critical areas and the maximum principle stresses are 193.37 MPa and 151.66 MPa. These stresses are smaller than $235 \mathrm{MPa}$, the yield stress of STAM 390, so it is concluded that the frame structure is safe.

3) The proposed method yields reasonable results for a valid FE model of a motorcycle frame and provides a valid relationship between dynamic characteristics, material properties, and geometry of the frame. The application of this presented method provides a useful tool for the analysis and new design of a motorcycle frame in automotive industry.

\section{REFERENCES}

[1] Hill, C.W.A., Jones, G.R., Schilling, M.A., 2016, "Strategic Management: Theory: An Integrated Approach", $12^{\text {th }}$ ed., USA: Cengage Learning.

[2] Hirz, M., Dietrich, W., Gfrerrer, A., Lang, J., 2013, "Integrated Computer-Aided Design in Automotive Development: Development Processes, Geometric Fundamentals, Methods of CAD, Knowledge-Based Engineering Data Management", Berlin Heidelberg Berlin Heidelberg: Springer-Verlag. 
[3] McLeod, P., 2001, "Availability and Capabilities of 'Low-End' Virtual Prototyping”, Wolfson School of Mechanical and Manufacturing Engineering Loughborough University, Loughborough, Leics: Prime Faraday Partnership.

[4] Rashid, H., Abdullah, A.H., Noh, M.H.M., Hamid, A.H.A., Abidin, N.M.Z., 2012, "Design of a superbike paddock stand using CAD and CAE tools", International Journal of Automotive and Mechanical Engineering, Vol. 5 (Jan-June), pp. 670-679.

[5] Cali, M., Oliveri, S.M., 2017, "Application of an effective SIMP method with filtering for topology optimization of motorcycle tubular frame", International review of Mechanical Engineering, Vol. 11, Issue 11, November, pp. 836-844.

[6] Doria, A., Taraborrelli, L., 2016, "The twist axis of frames with particular application to motorcycles", Proceedings of the institution of mechanical engineers, part C: Journal of mechanical engineering science, Vol. 230, Issue 17, 1 October, pp. 3026-3039.

[7] Katdare, P., Shilwant, S.C., 2015, "Design Optimization of Two Wheeler (Bike) Chassis", International Engineering Research Journal (IERJ), Vol. 2, pp. 4273-4277.

[8] Scappaticci, L., Bartolini, N., Guglielmino, E., Risitano, G., 2017, "Structural optimization of a motorcycle chassis by pattern search algorithm", Engineering Optimization, Vol. 49, Issue 8, 3 August, pp. 1373-1387.

[9] Bala Manikandan, C., Balamurugan, S., Balamurugan, P., Beneston, 2018, "Weight reduction of motorcycle frame by topology optimization", Journal of achievments in materials and manufacturing engineering, Vol. 91, Issue 2, pp. 67-77.

[10] Li, S., Feng, X., 2020, "Study of structural optimization design on a certain vehicle body-in-white based on static performance and modal analysis", Mechanical system and signal processing, Vol. 135, 1 January, article number 106405.

[11] Jelani, K.M., Razip, M.H.M., Nazri1, N.A., Sani, M.S.M., Yasar, M., 2019, "Dynamics investigation on motorcycle chassis based on Finite Element (FE) modeling and updating", IOP Conf. Series: Materials Science and Engineering, 469 (2019) 012103, pp. 1-10, doi:10.1088/1757-899X/469/1/012103.

[12] Covill, D., Begg, S., Elton, E., Milne, M., Morris, M., Katz, T., 2014, "Parametric finite element analysis of bicycle frame geometries", Procedia Engineering, Vol. 72 , pp. $441-446$.

[13] Greening, P.D., 1999, "Dynamic finite element modeling and updating of load structures", Dissertation, Departments of Aerospace and Civil Engineering University of Brisbol.

[14] Mohankumar, D., Sabarish, R., Kumar, M.P.J., 2018, "Structural and modal analysis of scooter frame", International Journal of Pure and Applied Mathematics, Vol. 118 (18), pp. 935-943.

[15] Hatifi, M.M., Firdaus, M.H., Razlan, A.Y., 2014, "Modal analysis of dissimilar plate metal joining with different thickness using MIG welding", International Journal of Automotive and Mechanical Engineering, Vol. 9 (Jan-June), pp. 1723-1733.

[16] Bucchi, F., Ceru, F., 2017, "Stability analysis of a novel four-wheeled motorcycle in straight running", Meccanica, Vol. 52, Issue 11-12, 1 September, pp. 2603-2613.

[17] Abdullah, N.A.Z., Sani, M.S.M., Husain, N.A., Rahman, M.M., Zaman, I., 2017, "Dynamics properties of a Go-kart chassis structure and its prediction improvement using model updating approach", International Journal of Automotive and Mechanical Engineering, Vol. 14 (1), pp. 3887-3897.

[18] Liu, C.W., Huston, R.L., 2011, "Principles of vibration analysis: with application in automotive engineering", Warrendale, Pennsylvania: SAE International.

[19] Ewins, D.J., 2000, Modal Testing, 2 ${ }^{\text {nd }}$ ed. Research Studies Press Baldock, UK

[20] He J, Fu ZF (2001), Modal analysis, Oxford: Butterworth-Heinemann.

[21] Wang, E., Nelson, T., Rauch, R., 2004, "Back to elements - tetrahedra vs hexahedra", retrieved from https://support.ansys.com/staticassets/ANSYS/staticass ets/resourcelibrary/confpaper/2004-Int-ANSYS-Conf9.PDF; 25 August, 2018.

[22] Wibowo, A., Setyanto, D., 2018, "Modal and stress analysis of X71A sport motorcycle frame body virtual testing model based on finite element analysis", International journal of applied engineering research, Vol. 13(18), pp. 13466-13474.

[23] Cossalter, V., 2007, "Motorcycle Dynamics", $2^{\text {nd }}$ ed. USA: Lulu.com 